\title{
A Simulator of the Manufacturing of Induction Motors
}

\author{
Christopher L. Tucci, Jeffrey H. Lang, Member, IEEE, Richard \\ D. Tabors, and James L. Kirtley, Jr., Senior Member, IEEE
}

\begin{abstract}
This paper presents a simulator of the manufacturing process of induction motors. Its main purpose is to provide feedback in the form of motor cost and production scheduling during the process of motor design. The paper concentrates on modeling and simulating a factory, modeling production costs, and providing examples of how the design of electric motors can be improved by taking manufacturing information into account via software. The simulator uses principles of system dynamics and technical cost modeling to model the flows of materials and the evolution of product through manufacturing stages across the factory floor. The inputs to the simulator are blueprint data for motor design, and the status of the factory. The output from the simulator is cost and schedule information. The simulator also provides a mechanism whereby design variables can be tested for variations that produce cost improvements.
\end{abstract}

\section{INTRODUCTION}

C URRENT practice in the electric motor industry is to design motors with little or no input from manufacturing, and with little or no integration of cost accounting. Design facilities are often quite remote from manufacturing facilities. Motor designers typically design the motor on their own, and then send the design to the manufacturing facility. The manufacturers may then reject the design, ask for modifications, or accept it. After some period of negotiation and modification, the design is approved, and the cost and schedule are determined by manufacturing engineers and accountants.

This paper demonstrates a shortening of the design/manufacturing feedback process, as opposed to the design process itself, via software that models the manufacturing of an electric motor. The outputs from this manufacturing simulator, as we have called it, are the feasibility of the design, the cost of producing the order, the schedule requirements, and sensitivities of some design and manufacturing variables. The method described herein can be applied in a general way to any computer-aided design system to add several extra dimensions-for example, cost-to previously existing design considerations.

Paper MSDAD 92-005, approved by the Industrial Automation and Control Committee of the IEEE Industry Applications Society for presentation at the 1991 Industry Applications Society Annual Meeting, Dearborn, MI, USA. Manuscript released for publication September 30, 1993. This paper is based on the S.M. Thesis of C. L. Tucci.

C. L. Tucci is with the Sloan School of Management, Massachusetts Institute of Technology, Cambridge, MA 02139 USA.

J. H. Lang, R. D. Tabors, and J. L. Kirtley, Jr., are with the Laboratory for Electromagnetic and Electronic Systems, Massachusetts Institute of Technology, Cambridge, MA 02139 USA.

IEEE Log Number 9400146
In this paper, we assert that cost and schedule information can be calculated by simulating the operation of a real factory and examining the details of the operation. That is, the simulator should strive to provide a one-to-one correspondence with the operation of the factory. Using a simulator such as this, a manufacturer of electric motors can provide a better match between customer desires or requirements, and manufacturing possibilities or constraints.

There are several reasons to pursue this line of research. First, the communication or relationship between motor manufacturers and customers may be improved. Second, the information provided from modeling motor performance and simulating the manufacturing process is valuable and may produce lower-cost and higher-quality motor designs. This value stems from the fact that a variety of designs or factory configurations can be examined quickly, providing a proxy for expensive production tests.

Another reason for studying models such as the one presented here is that an integrated design, manufacturing, and accounting system for electric motors, and other manufactured goods, will allow for quicker and more flexible design. This is accomplished by examining previous designs, providing a mechanism for synthesis of new designs, simulating the manufacturing process for cost and schedule, and efficiently storing and scaling design and manufacturing information.

In the past, little research has considered simultaneous design and manufacturing optimization, and few papers have demonstrated the cost component incorporated into the models [11]. Reference [14] developed software for the design of electric motors that automatically compared some design variables to performance requirements, although it did not address manufacturing. Reference [15] presents information on the manufacturing process, but restricts its attention to very large $\mathrm{AC}$ motors and generators.

There has not been much recent work on the manufacture of small-sized to medium-sized electric motors, nor is it apparent that many producers have used manufacturing information or simulated the manufacturing process to improve design per se, although [4] reports that an American motor manufacturer has demonstrated unusually short design-to-manufacture turnaround times.

In contrast, this paper specifically focuses on incorporating manufacturing and cost accounting into the design process for electric motors. This is accomplished by developing a running-time simulator of the factory and validating it against 


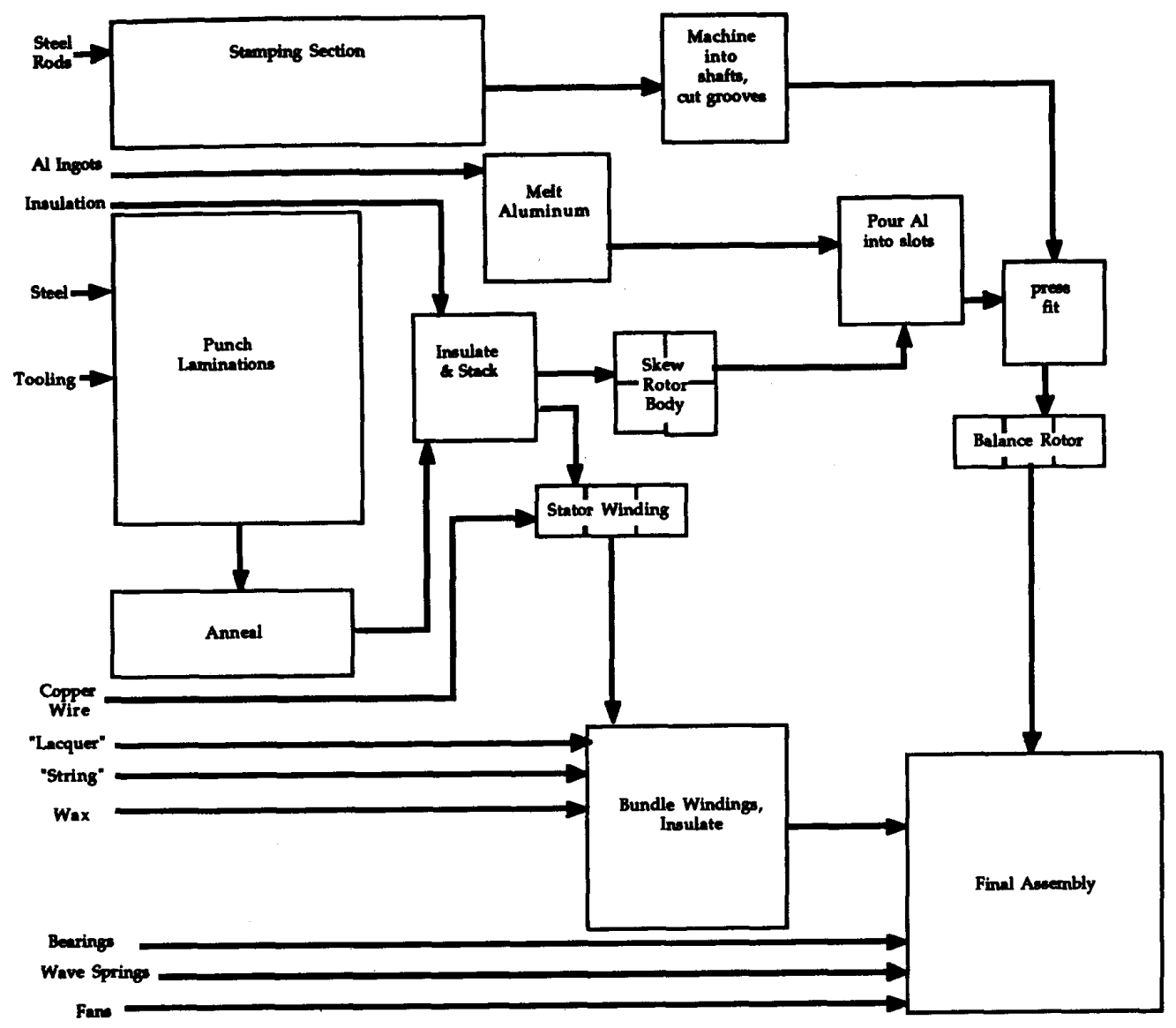

Fig. 1. A simplified factory flow model.

data from real factories. In addition, we demonstrate how the simulator can be used in several different applications. Finally, the simulator is employed in a larger computer-aided motor design system in [10].

\section{MODEL OF THE FACTORY}

Several assumptions underlie the modeling effort, and can be summarized by the convention that the whole is equal to the sum of the parts. For the factory, this means that all aspects of production can be determined by aggregating the pieces that make up production; the manufacturing process can be broken down in a recursive manner into smaller parts or stages. The factory is assumed to comprise these stages wherein each part of the motor is built out of the raw materials [1], [6], [7], [15]. In this model, the stages are linked together; the output of one stage becomes the input to the next [3]. We do not assume restrictions on multiple parents or children of stages.

Fig. 1 demonstrates a simple model of a factory for induction motors, presented in a condensed form that does not show all the dependencies and feedback effects. While this model is specific to a particular factory, the general method described for modeling a factory as a limited set of manufacturing machines linked together in predictable ways will be the same for almost all motor producers. Each stage of the manufacturing process is assumed to process inputs into outputs at a rate that is dependent on exogenous design variables such as shaft length, and factory parameters such as machine type, and endogenously determined status variables such as feedback from downstream stages.

As an example, consider the "Bundle" stage of Fig. 1. This stage takes raw materials such as lacquer, string, and wax out of internal stocks and combines them at a certain rate with partially finished wound stators, or stator cores. The rate that the workers convert lacquer, string, wax, and stator cores into stators is affected by the rate at which they can bundle the wires, the inventory of stator cores, the number of turns, and the number of poles.

Fig. 2 shows detailed information on the bundling stage. Ignoring the inventories for lacquer, string, and wax, the stage converts stator cores to stators at a rate that depends on the number of stator cores and the bundling rate. The bundling activity requires, for example, three full-time workers, utilizing machines costing $\$ 1000$ and drawing negligible electricity, and taking up 1700 square feet in the factory. There is no tooling delay and no maintenance costs or delays. It only remains to determine the functional form of the bundling rate itself, 


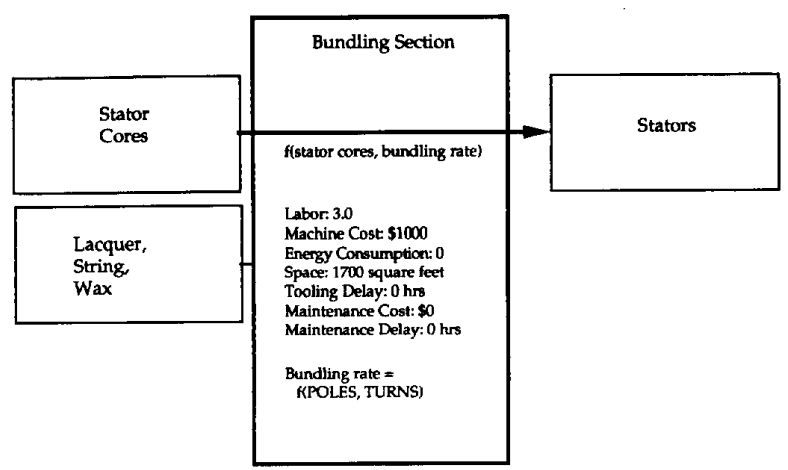

Fig. 2. Detailed functional form and costs for bundling.

which depends on the number of turns and the number of poles, which must be specified.

The goal of the manufacturing simulator is to determine the effects of design changes on the manufacturing process. In order to estimate the total effect on the factory, it is necessary to determine the effects of design changes on the speed at which each stage produces its part. This can be accomplished via a statistical regression of service rates, that is, the number of parts produced per unit time, on design parameters, and can be performed as part of a manufacturing experiment or during the course of production. To illustrate the process, we have generated an amalgamated set of motor designs and service rates based on measurements and interviews with engineers in several factories. A sample functional form for the bundling rate discussed above based on this data set is

BUNDLED $=135.45-12.683 \ln ($ POLES $)$

$$
-8.218 \ln (\text { TURNS) }
$$

where BUNDLED is the number of stator cores bundled per hour, POLES is the number of poles in the motor, and TURNS is the number of series turns in a bundle.

The significance of other design variables can also be tested using this statistical approach. For example, the manufacturing engineer may like to know whether the size of the outer stator radius, OSR, has an appreciable effect on the number of stator windings bundled per hour. This can be tested directly, as shown in

$$
\begin{aligned}
\text { BUNDLED }= & 135.422-12.683 \ln (\text { POLES }) \\
& \begin{array}{c}
(19.611) \\
(-7.05)
\end{array} \\
& -8.218 \ln (\text { TURNS })+0.005 \ln (\text { OSR }) \\
(-11.734) & (0.005)
\end{aligned}
$$

T-statistics, a measure of the significance of the explanatory effect of an independent variable [9], are shown in parentheses below the terms. In (2), OSR is not different from zero at the $95 \%$ level of confidence. Note that a t-statistic of absolute value greater than 2 means that the approximate $95 \%$ confidence interval of the coefficient of the variable does not include 0 , that is, that the variable has an explanatory effect on the dependent variable. This is based on a sample containing at least 30 observations.

Once the service rates have been estimated to the satisfaction of the engineer, they can serve as inputs to the

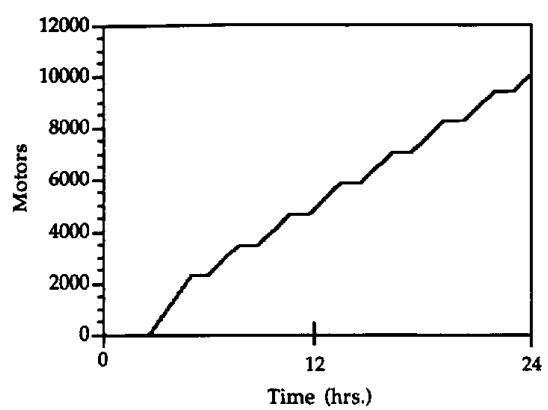

Fig. 3. Motor accumulation over time.

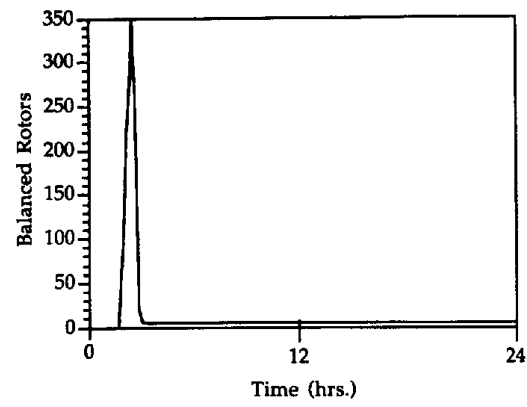

Fig. 4. Balanced rotors in internal stocks over time.

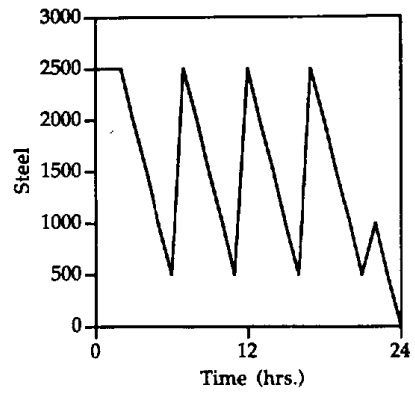

Fig. 5. Steel sheet inventories over time.

manufacturing simulator. The simulator follows a discreteevent system dynamics paradigm [8] in which at each instant of simulated time, the flows of materials from one stage to the next are determined via the service rates, and stocks are simultaneously accumulated or depleted. In this progression, the final assembly area begins to accumulate finished motors. When the number of motors produced equals the number of motors requested, the simulator terminates.

Figs. 3-5 demonstrate the accumulation of motors, the accumulation and depletion of an internal inventory of balanced rotors, and the periodic arrival and depletion of steel sheets, respectively. The figures also show such factors as how long it takes to manufacture the order and how much material is used in the process. Further, by varying the design variables, holding performance constant, the effect of design variable changes on the manufacturing process can be determined. 
Returning to the bundling stage for a final example, consider the effects of the number of turns and poles on the service rate. These design variables determine how quickly the raw materials are depleted and how many stators can be bundled per unit time. Feedback or control loop effects can be introduced, as in a real factory. When the number of bundled stators relative to the number of balanced rotors becomes excessive, for example, the factory could divert its resources away from bundling to other areas experiencing delays. This can be modeled by either stopping production at the stage in question or, if feasible, shifting workers and increasing production at the bottleneck stage.

\section{THE COST MODEL}

A cost assumption analogous to that which allowed the decomposition of the factory is that each cost can be ascertained by examining the underlying costs that contribute to it. That is, each cost can be determined from established engineering and cost accounting principles based on the cost of the underlying processes.

Another assumption of our cost accounting is that detailed information is not only desirable but necessary when making cost comparisons and decisions [2]. While asserting this here, we attempt to quantify the benefit in [13]. In particular, [13] demonstrates the distortions introduced by using other wellknown cost accounting methods, such as materials [11] or labor burdening, both of which are very much in current practice.

The informed motor designer or engineering manager is therefore interested in a much more detailed analysis of the various contributions to the cost of a motor. Our model breaks down component costs into a variety of categories, as displayed in Table I. The table is a sample of the output of the program for a 3-hp 4-pole 36-slot 132-turn 230-V motor based on the production model specified in Figs. 1 and 2. Costs in this case are divided between fixed costs, which are those that the manufacturer pays whether or not any motors are produced, and variable costs, which are those that depend on the production run [2].

As an example of how costs are aggregated, consider the costs of operating the stages specified in Section II. A breakdown of the component cost factors for the bundling stage is displayed in Fig. 2. In our model, all material flows, the amount of labor required in each stage, the amount of energy and space consumed by each stage, the cost of the manufacturing machines, the tooling and maintenance costs, and so on, are all tracked.

The variable costs are determined by aggregating the factors of production across all of the stages and multiplying by the factor prices given as inputs to the model. For example, the cost of copper can be determined by adding together copper used in the winding of stators and possibly rotors, and multiplying by the price of copper wire. The amount used will depend critically upon the design, since large motors with wide slots will necessarily consume more copper wire than small motors. Likewise, the variable cost of labor, taken to be total direct wages paid, could vary between designs that
TABLE I

Tracking Variable and Fixed Costs

\begin{tabular}{|c|c|c|c|}
\hline $\begin{array}{l}\text { Variable Cost } \\
\text { Elements }\end{array}$ & $\$ /$ motor & $\$ /$ run & percent \\
\hline Material Cost & 14.84 & 148439.94 & 64.68 \\
\hline Utility Cost & 0.02 & 189.40 & 0.08 \\
\hline $\begin{array}{l}\text { Direct Labor } \\
\text { Cost }\end{array}$ & 1.24 & 12396.60 & 5.40 \\
\hline $\begin{array}{l}\text { Total Variable } \\
\text { Cost }\end{array}$ & 16.10 & 161025.94 & 70.16 \\
\hline $\begin{array}{l}\text { Fixed Cost } \\
\text { Elements }\end{array}$ & $\$ /$ motor & $\$ /$ run & percent \\
\hline Factory Cost & 2.12 & 21201.17 & 9.24 \\
\hline Tooling Cost & 1.70 & 17000.00 & 7.41 \\
\hline $\begin{array}{l}\text { Overhead Labor } \\
\text { Cost }\end{array}$ & 1.73 & 17275.38 & 7.53 \\
\hline Building Cost & 0.04 & 386.88 & 0.17 \\
\hline Installation Cost & 0.53 & 5300.29 & 2.31 \\
\hline $\begin{array}{l}\text { Auxiliary } \\
\text { Equipment Cost }\end{array}$ & 0.42 & 4240.23 & 1.85 \\
\hline $\begin{array}{l}\text { Maintenance } \\
\text { Cost }\end{array}$ & 0.12 & 1229.67 & 0.54 \\
\hline Cost of Capital & 0.19 & 1852.25 & 0.81 \\
\hline Total Fixed Cost & 6.85 & 68485.88 & 29.84 \\
\hline Total Cost & 22.95 & 229511.81 & 100.00 \\
\hline
\end{tabular}

were more or less labor intensive. This cost is calculated by adding all labor performed across the stages and multiplying by the wage rate.

Fixed costs are computed by simply noting how long the factory is utilized in the production of the motor, and dividing the cost of running and owning the factory between the number of motors produced. In addition to the standard fixed costs such as energy and labor benefits, we compute opportunity costs incurred by producing. For example, the space occupied by the factory could be rented out for other purposes. Using the factory for production therefore entails a fixed opportunity cost for which an accounting must be made. Note that not all fixed cost information may be used in actual capital equipment decisions, but may be useful for design decisions.

There are several good reasons for specifying the cost of a motor using the system explained above. The most important reason is that the estimates of the effects of design changes on production are far more accurate than other methods in current use. For example, when a firm burdens labor, laborsaving designs seem very attractive compared to capital-saving designs. However, the estimated savings are rarely realized since the substantial fixed and nonlabor variable costs do not change. The only thing that changes is the burden rate, which necessarily rises. This can lead to an "adverse selection" problem where more and more labor-saving devices are used, which only serve to raise the burden rate, which causes a more desperate search for labor saving measures, and so on. In addition to the adverse selection problem, we have found that production costs burdened to labor can be widely recognized throughout the factory. This may lead to less than optimal labor relations.

\section{RESULTS AND APPLICATIONS}

Once the simulator of the manufacturing process and the computation of the cost of producing the design under con- 
TABLE II

Sensitivity Analysis of Motor Design

\begin{tabular}{lcc}
\hline Design Variable & Sensitivity Up & Sensitivity Down \\
\hline Cooling Fins & +0.000000 & +0.000000 \\
Lamination Stack & +0.041943 & -0.042765 \\
Length & +0.000000 & +0.000001 \\
Outer Stator Radius & -0.000575 & +0.000834 \\
Number of Poles & +0.872620 & -0.949624 \\
Shaft Length & -0.004839 & +0.000000 \\
Shaft Radius & +0.000703 & -0.000708 \\
Number of Slots & -0.064953 & +0.071760 \\
Lamination Thickness & +0.000396 & -0.000533 \\
Number of Turns & &
\end{tabular}

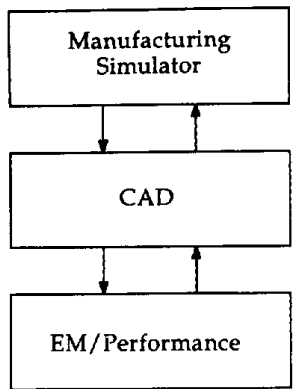

Fig. 6. System analysis of induction motors.

sideration have been completed, the simulator provides a mechanism whereby design variables can be tested for slight variations that produce cost improvements. This is done by simulating the order with each of the design variables modified slightly in each direction. The total cost of producing the order is compared to the original to determine price sensitivity.

The sensitivity analysis information can be used by designers when deciding between alternative methods of improving performance or cutting cost when designing a new motor. For example, Table II demonstrates that given the design discussed in Table I, the cost of production is only sensitive to one variable in the neighborhood of the design. A designer might interpret this information as a warning to avoid increasing the shaft length in order to increase performance if possible, since it is the most costly design variable. Of course, the designer must trade this cost off against the effectiveness or desirability of increasing the shaft length, which may produce a more than proportionate increase in the performance [5].

As part of the larger system shown in Fig. 6, a large number of motors can be analyzed with performance requirements plotted against cost simultaneously to produce tradeoff curves [10]. One such curve is displayed in Fig. 7 which displays cost against inefficiency for a number of 3-hp 4-pole 230-V motors. One could trace out a production frontier by drawing a curve along the most desirable points: the points closest to the origin. The design discussed in Tables I and II is marked with a star.

A design engineer may use this information to determine if an appropriate motor exists already, to obtain a rough estimate of the cost of a new design, or to choose from among many designs [5]. In particular, the production of tradeoff curves allows the engineers to determine the frontier of the technology

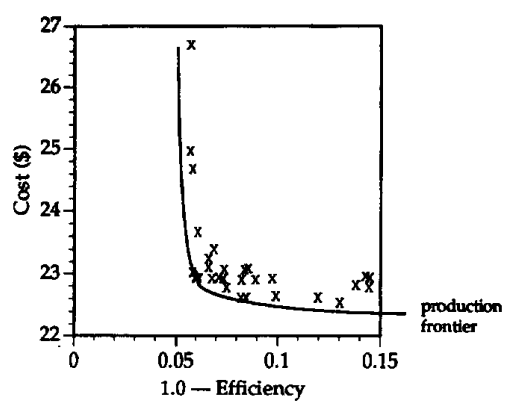

Fig. 7. Cost versus inefficiency for 3-hp 4-pole 230-Volt motors.

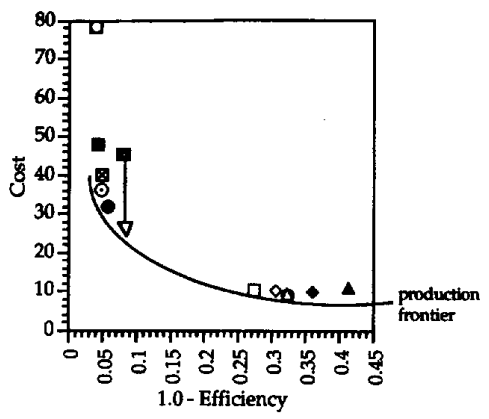

Fig. 8. Changes in factor prices that change the frontier.

for a given motor: namely, what the lower limit of cost may be for a new order given the customer's requirements and today's technology. To examine the effect of factor price changes on design decisions, one can plot the production frontier before and after the hypothesized price changes, as shown in Fig. 8. Here the design represented by the black square with white cross is not on the frontier when steel prices are low. But if the price of steel were to double, the design moves onto the frontier and becomes a very desirable motor to produce.

This information may also be useful to price-taking firms deciding whether to accept bids from customers [13], as shown in Fig. 9. The areas in this figure are based on average variable cost and average total cost. The firm should accept orders falling above the top curve, such as 4000 motors at $\$ 100$ apiece. The firm should reject any order falling below the bottom curve, such as 1000 motors at $\$ 25$ apiece. In between is an area that the firm can accept over the short term since it covers fixed costs, but cannot continue over the long term.

Another application in which the simulator is useful is as a scheduling tool. We have developed a priority-queue model in which design "orders" can be submitted at various priority levels to determine when an order could be filled given the current outstanding orders. This information may be useful to manufacturing engineers as a more efficient way of scheduling the factory. It may also be helpful to customer contacts when planning with a customer when a particular order can be filled.

In the future, the analysis may be applied to process optimization to allow manufacturing engineers to assess the effects of changes in the factory itself. For example, the hypothesis of improving factory throughput by adding parallel 


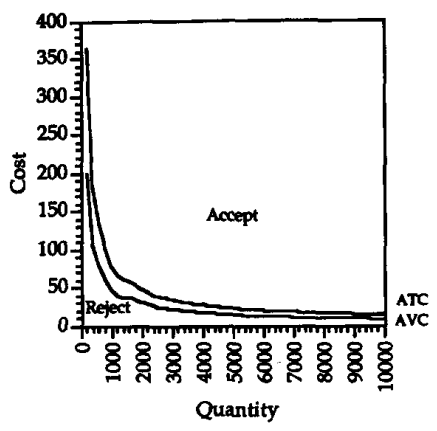

Fig. 9. Bid acceptance and rejection regions.

equipment could be tested before the investment in the new equipment is actually made.

\section{CONCLUSION}

In summary, we have developed the capability of simulating the manufacturing of induction motors. The simulator takes blueprint design data and the state of the factory as input, and produces cost and scheduling information as output. This cost and scheduling information, used by the designers in the form of sensitivity analysis and design tradeoffs, will, it is hoped, provide four benefits. The first benefit is improved communication between design and manufacturing, which may lead to substantial productivity rises for motor manufacturers [12]. The ability to preview manufacturing schedules and the lessening of rejected designs should contribute to this effect. The second benefit is improved customer relations through more accurate scheduling and more accurate pricing/bid responses. The third benefit may be lower cost and higher quality motors, since alternative designs providing the same performance at a lower cost or the same cost at higher performance can be explored easily through use of the simulator. Finally, a simulator such as this should in the end allow a manufacturer to produce designs in a more flexible way, with the ability to more quickly try new designs, the ability to respond more efficiently to customer requests, and the possibility of exploring different factory configurations.

\section{ACKNOWLEDGMENT}

The authors wish to acknowledge the MIT Leaders for Manufacturing Program for their support of this work.

\section{REFERENCES}

[1] O. N. Bessmertnaya, "The sad 112, 132 line for final assembly of electric motors," Elektrotekhnika, vol. 58, no. 6, p. 93, 1987.

[2] J. V. Busch and F. R. Field, III, "Technical cost modeling," in Blow Molding Handbook, X. Rosato and X. Rosato, Eds. New York: Hansen, 1989, pp. 839-871.

[3] R. N. Chavali, S. Keswani, and S. C. Bose, "Modeling and optimization of a flexible manufacturing system," J. Appl. Manufactur. Syst., pp. 25-27, Winter 1990.

[4] A. Farnham, "Baldor's success: Made in the USA," Fortune, pp. 101-104, July 17, 1989.

[5] F. R. Field and R. de Neufville, "Materials selection-Maximizing overall utiljty," Metals Materials, pp. 378-382, June 1988.
[6] I. V. Golovkin et al., "Equipment system for mechanization of the production processes of electric motor shafts," Elektrotekhnika, vol. 58, no, 6, p. 91,1987

[7] I. D. Gurevich and I. L. Kats, "Automating the machining of inductionmotor stator cores," Elektrotekhnika, vol. 58, no. 2, p. 62, 1986.

[8] A. Legasto, J. Forrester, and J. Lyneis, Eds., System Dynamics. Amsterdam: North-Holland, 1980.

[9] B. W. Lindgren, Statistical Theory, 3rd ed. New York: Macmillan, 1976.

[10] J. A. Moses, J. L. Kirtley, Jr., J. H. Lang, R. D. Tabors, and F. de Cuadra, "A computer-based design assistant for induction motors," in Conf. Rec. 1991 IEEE IAS Annu. Meet., Dearborn, MI, Oct. 1991.

[11] M. Nurdin, M. Poloujadoff, and A. Faure, "Synthesis of squirrel cage motors: A key to optimization," IEEE Trans. Energy Conversion, vol. 6 , pp. 327-333, June 1991.

[12] N. R. Philips, "Old manufacturing facility sheds inefficient practices and implements structured management procedures without capital equipment expenditure," Ind. Eng., pp. 26-29, 69, Jan. 1988.

[13] C. L. Tucci, "Adding manufacturing and cost accounting to the design process of induction motors," S.M, thesis, Technol. Policy, MTT, 1991.

[14] C. G. Veinott, Computer-Aided Design of Electrical Machines. Cambridge, MA: MIT Press, 1972.

[15] J. H. Walker, Large AC Machines: Design, Manufacture, and Operation. New Delhi: Bharat Heavy Electrics, 1979.

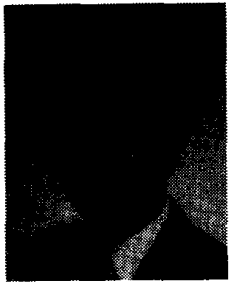

Christopher L. Tucci received the B.A. degree in mathematical sciences, the A.B. degree in music, and the M.S. degree in computer science from Stanford University, Stanford, CA, USA; and the S.M. degree in technology \& policy from the Massachusetts Institute of Technology, Cambridge.

$\mathrm{He}$ is currently a doctoral candidate in the Management of Technological Innovation group in the Sloan School of Management at M.I.T. His current research focuses on incentives to engage in $R \& D$ collaboration and form strategic technology alliances with competitors across national boundaries.

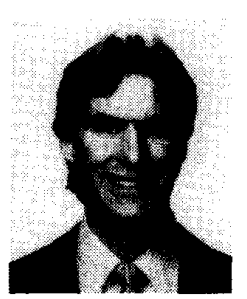

Jeffrey H. Lang (S'78-M'80) received the B.S., M.S., and Ph.D. degrees in electrical engineering from the Massachusetts Institute of Technology, Cambridge, USA, in 1975, 1977, and 1979, respectively.

In 1980 he joined the Department of Electrical Engineering and Computer Science at the Massachusetts Institute of Technology, where he is now Professor of Electrical Engineering. His research involves the analysis, design, and control of physical systems, and currently concentrates on electromechanical systems with application to traditional electric machine systems, micro sensors and actuators, and flexible structures.

Dr. Lang is a member of Eta Kappa Nu and Tau Beta Pi. From 1977 through 1979 he held a Fannie and John Hertz Foundation Fellowship. 


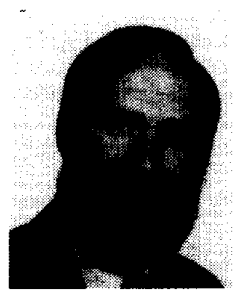

Richard D. Tabors was born in Cleveland, $\mathrm{OH}$, USA on October 16, 1943. He received the B.A degree in biology from Dartmouth College, and the M.A. and Ph.D. degrees in geography and economics from the Maxwell School of Syracuse University in 1965,1970 , and 1971 , respectively.

From 1970 to 1976 he was on the Faculty of Harvard University where he worked on Environmental and Resource Planning. From 1976 to the present he has been at M.I.T. where he is Senio Research Engineer and Assistant Director of the Laboratory for Electromagnetic and Electronic Systems, and teaches Electrical Engineeringas well as in the Technology and Policy Program. He is author of a number of papers on electric power planning and pricing, and co-autho with Fred C. Schweppe, Michael C. Caramanis, and Roger E. Bohn of Spot Pricing of Electricity (Norwell, MA: Kluwer Academic, 1988). In addition, he is the co-author with Thomas H. Lee and Ben C. Ball, Jr., of Energy Aftermath (Cambridge, MA: Harvard Business School Press, 1989). He has also written extensively on environmental planning. He is a founder and principal of Tabors Caramanis \& Associates of Cambridge, MA.

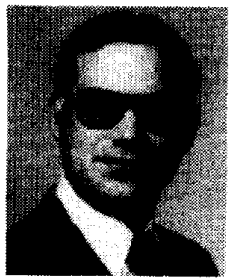

James L. Kirtley, Jr. (S'69-M'71-SM'80) received the S.B. degree from the Massachusetts Institute of Technology, Cambridge, USA, in 1968, and the $\mathrm{Ph} . \mathrm{D}$. degree in electrical engineering in 1971.

He joined the M.I.T. Faculty in 1971 , and is Associate Professor in the Department of Electrical Engineering and Computer Science. During 1974 and 1975 he worked as a Generator Engineer for General Electric, Large Steam Turbine Generator Department, Schenectady, NY. His areas of specialization are electric machinery and electric power systems engineering. He has played a major role in the program at M.I.T. to develop generators with superconducting field windings.

Dr. Kirtley is Secretary of the Rotating Machinery Committee of the Power Engineering Society, and a member of the Editorial Board of the journal Electric Machines and Power Systems. He also served as Conference Chairman of IECM ' $90 . \mathrm{He}$ is a Registered Professional Engineer in Massachusetts. 